\title{
Atomistic Modeling of RuAl and (RuNi)Al alloys
}

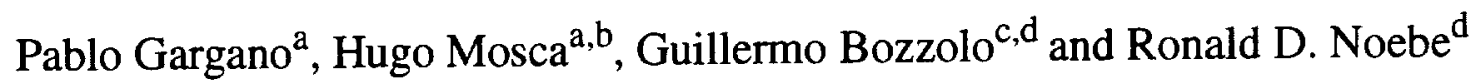

${ }^{a}$ U. A. Materiales, Centro Atómico Constituyentes, Comisión Nacional de Energía Atómica, Av. Del Libertador 8250, 1429 Buenos Aires, Argentina

bDto. de Ingeniería Mecánica y Naval - FIUBA, Paseo Colón 850, 1063 Buenos Aires, Argentina ${ }^{c}$ Ohio Aerospace Institute, 22800 Cedar Point Rd., Cleveland, OH 44142, USA

dNASA Glenn Research Center at Lewis Field, Cleveland OH 44135, USA

Keywords: Intermetallics, RuAl, Computational Modeling

\begin{abstract}
Atomistic modeling of RuAl and RuAlNi alloys, using the BFS method for alloys is performed. The lattice parameter and energy of formation of $\mathrm{B} 2 \mathrm{RuAl}$ as a function of stoichiometry and the lattice parameter of $\left(\mathrm{Ru}_{50-\mathrm{x}} \mathrm{Ni}_{\mathrm{x}}\right) \mathrm{Al}_{50}$ alloys as a function of $\mathrm{Ni}$ concentration are computed. BFSbased Monte Carlo simulations indicate that compositions close to $\mathrm{Ru}_{25} \mathrm{Ni}_{25} \mathrm{Al}_{50}$ are single phase with no obvious evidence of a miscibility gap and separation of the individual B2 phases.
\end{abstract}

\section{Introduction}

In comparison with nickel or cobalt aluminides, $\mathrm{B} 2 \mathrm{RuAl}$ has appreciable room-temperature toughness and plasticity and maintains considerable strength at high temperatures [1-2]. These properties, in combination with excellent oxidation resistance [3], make this alloy a potential candidate for aerospace applications though cost and high density are a significant concern. In an effort to drive down both cost and weight and improve upon its other properties, several studies [4-6] have looked at alloying schemes for replacing $\mathrm{Ru}$ or Al with other elements that generally form an isostructural B2 phase such as $\mathrm{Co}$ and $\mathrm{Fe}$ for $\mathrm{Ru}$ and $\mathrm{Ti}$ for $\mathrm{Al}$. But by far, the most widely studied ternary alloying addition has been $\mathrm{Ni}$ [7-13]. Even then, there is disagreement as to the structure of ternary Ni-Ru-Al alloys that exist between the NiAl and RuAl B2-phase fields. 
Chakravorty and West [9-10] have reported a miscibility gap centered between the two binary phases resulting in a region consisting of two distinct B2 compounds. In apparent agreement, Sabariz and Taylor [11] have also observed a two-phase alloy at the composition $\mathrm{Ni}_{25} \mathrm{Ru}_{25} \mathrm{Al}_{50}$. While Homer et al. [13] found results similar to Chakravorty and West [10] in that many, but not all, of the ternary compounds seemed to exhibit two distinct components, the evidence seemed to overwhelmingly suggest coring as opposed to actual formation of two distinct B2 phases. Furthermore, a sample within the miscibility gap claimed by Chakravorty and West was heavily milled and annealed so that diffusion distances would be much smaller and a better opportunity for obtaining a near equilibrium structure would exist. In this case, only a single B2 phase was observed. Furthermore, Liu et al. [12] observed only a single B2 phase across the (NiRu)Al system in mechanically alloyed samples when $\mathrm{Ni}$ was varied between 10 and 25 at.\%, indicating complete mutual solubility between $\mathrm{NiAl}$ and $\mathrm{RuAl}$.

Given the lack of agreement for even the structure of $\mathrm{Ni}-\mathrm{Ru}-\mathrm{Al}$ alloys and the generally scarce data for other ternary or higher order systems, it is useful to consider the development of a modeling effort to supplement the ongoing experimental work on RuAl alloys. In this area, we provide the necessary tools to perform such modeling, and use them to study the fundamental properties of $\mathrm{RuAl}$ and ( $\mathrm{Ru}, \mathrm{Ni}) \mathrm{Al}$ alloys. The modeling is performed within the framework of the BFS method for alloys, a quantum approximate method for the description of the energetics of complex systems at the atomic level, and is validated by comparison to experimental data.

\section{The BFS Method}

The BFS method for alloys [14] has been proven to be highly effective for the study of multicomponent systems. With the proper parameterization, it allows for an extremely economical, computationally simple, and physically sound description of the energetics of large collections of atoms. The BFS method is based on the assumption that the heat of formation, $\Delta H$, of a given collection of atoms is the sum of the contributions of each atom in the sample, $\varepsilon_{\mathrm{i}}$. Each contribution $\varepsilon_{\mathrm{i}}$ consists of two terms: a strain energy $\left(\varepsilon_{i}{ }^{S}\right)$ which accounts for the change in geometry with respect to a single monoatomic crystal of the reference atom, and a chemical energy $\left(\varepsilon_{i}{ }^{C}\right)$, linked by a coupling function $\left(g_{i}\right)$ so that $\varepsilon_{i}=\varepsilon_{i}{ }^{S}+g_{i} \varepsilon_{i}{ }^{C}$. Three parameters, equilibrium lattice parameter, cohesive energy, and bulk modulus, for each of the constituent 
atoms are needed in the general derivative structure of the compound being studied (in this case, bcc) in order to calculate these terms. The chemical energy accounts for the corresponding change in composition, considered as a defect in an otherwise pure crystal. The chemical 'defect' deals with pure and mixed bonds, therefore, two additional perturbative parameters $\left(\Delta_{\mathrm{AB}}\right.$ and $\Delta_{\mathrm{BA}}$ where $\mathrm{A}, \mathrm{B}=\mathrm{Ru}, \mathrm{Ni}, \mathrm{Al}$ ) are needed to describe these interactions. All the parameters (listed in Table 1) are determined with the Linearized-Augmented Plane Wave method (LAPW) [15]. An alternative set of parameters, obtained with the Linear-Muffin Tin Orbital method [16] can be found in Ref. 17. We refer the reader to Ref. 14 for a detailed description of the BFS method and its parameterization, and Ref. 18 for details on Monte Carlo-Metropolis simulations using BFS.

\section{Results and Discussion}

A general comparison between the LAPW values and other calculated and experimental values of the lattice parameter, cohesive energy, and bulk modulus for RuAl [19-33] is shown in Table 2. The LAPW calculations correctly reproduce the value of the lattice parameter $a_{0}$ for stoichiometric RuAl. Although $\mathrm{Ru}$ and $\mathrm{Al}$ do not exist in the bcc phase, the lattice parameter of the computed bcc-Ru and bcc-Al are both larger than the equilibrium lattice parameter of $\mathrm{RuAl}$ (a $1.4 \%$ difference with respect to bcc-Ru, and a $7.8 \%$ difference for bcc-Al). The predicted value of $a_{0}, 3.005 \AA$, compares well with the experimental values, $2.95 \AA$ [32] to $3.03 \AA$ [20]. Considering the typical deviations in first-principles values for the energy of formation, the LAPW prediction compares well with the experimental value of $1.28 \mathrm{eV} /$ atom [21]. The LAPW input, validated in Table 2 , is used for the determination of the BFS perturbative parameters $\Delta_{\mathrm{AB}}$ and $\Delta_{\mathrm{BA}}$, listed in Table 1 for all possible pair combinations of $\mathrm{Ru}, \mathrm{Al}$, and $\mathrm{Ni}$.

We first apply the parameters listed in Table 1 to the analysis of the $\mathrm{B} 2 \mathrm{RuAl}$ phase field, by considering a large number of computational cells (defined previously in Ref. 14) including all possible defect structures for off-stoichiometric compositions. Whether structural vacancies are included or not in this set of possible configurations, it is seen that the RuAl phase is quite unstable with respect to changes in stoichiometry, in the sense that there is a noticeable change in energy of formation off stoichiometry. Furthermore, this change is more pronounced for Al-rich alloys, as can be seen in Fig. 1. For Ru-rich alloys, the lowest energy configurations correspond to substitutional alloys. The analysis suggests a trend towards phase separation, as configurations 
showing clustering of excess $\mathrm{Ru}$ atoms are energetically favored. This can be explained in terms of the individual BFS contributions $e_{i}(i=\mathrm{Ru}, \mathrm{Al})$ to the energy of formation of the computational cell. For B2 RuAl, $e_{R u}=-0.3383 \mathrm{eV} /$ atom and $e_{A l}=-1.6516 \mathrm{eV} / \mathrm{atom}$, indicating that both atoms contribute to the formation of the alloy (negative contributions to $\Delta H$ ). The 'weak' contribution of $\mathrm{Ru}$ atoms (compared to that of $\mathrm{Al}$ atoms) and the similarity between the atomic volume per atom in the $\mathrm{B} 2 \mathrm{RuAl}$ alloy and the atomic volume in a pure Ru crystal, lead to the phase separation observed for Ru-rich alloys [6]. To complete the analysis of B2 RuAl, Monte Carlo simulations using the NN approximation [18] were used to determine the melting temperature. It was found that the structure is highly ordered and stable up to $2300 \mathrm{~K}$, in excellent agreement with the experimental value of $2330 \mathrm{~K}$ [1].

Given the possiblity of 1 ) reducing the cost and weight of $\mathrm{RuAl}$ alloys through substitution of $\mathrm{Ru}$ with $\mathrm{Ni}, 2$ ) the potential to use RuAl as a reinforcing phase in other intermetallic systems, possibly even $\mathrm{NiAl}$ [7], and 3) given the controversy surrounding the phase structure of ternary Ru-Ni-Al alloys in the region between the two binary B2 phases NiAl and RuAl [9-13], Ru-Ni-Al would appear to be an ideal system for further theoretical analysis. While the following BFS analysis is applied to $\mathrm{Ni}$ additions to $\mathrm{RuAl}$, it should be noted that similar calculations can be easily performed for other ternary or higher order additions using, for example, the BFS parameters listed in Ref. 17.

For the ternary case, we first determine the preferred site occupancy for dilute additions of $\mathrm{Ni}$ in RuAl. Let $A(B)$ denote an $A$ atom occupying a site in the $B$ sublattice, and $A(B) B(C)$ the same, but with the displaced $B$ atom moving to a site in the $C$ sublattice. For $\left(\mathrm{Ru}_{50-\mathrm{x}} \mathrm{Ni}_{\mathrm{x}}\right) \mathrm{Al}_{50}$ alloys, $\mathrm{Ni}(\mathrm{Ru})=-0.98217 \mathrm{eV} / \mathrm{atom}$ and $\mathrm{Ni}(\mathrm{Al}) \mathrm{Al}(\mathrm{Ru})=-0.8780 \mathrm{eV} /$ atom, indicating that $\mathrm{Ni}$ prefers available $\mathrm{Ru}$ sites. However, for $\mathrm{Ru}_{50}\left(\mathrm{Al}_{50-\mathrm{x}} \mathrm{Ni}_{\mathrm{x}}\right)$ alloys $\mathrm{Ni}(\mathrm{Al})=-0.9600 \mathrm{eV} / \mathrm{atom}$ and $\mathrm{Ni}(\mathrm{Ru}) \mathrm{Ru}(\mathrm{Al})=-0.9513 \mathrm{eV} / \mathrm{atom}$, indicating a slight preference for $\mathrm{Al}$ sites, although the difference in energy is so small that it is difficult to conclude any obvious preference for either site under these conditions. The strong preference of $\mathrm{Ni}$ for $\mathrm{Ru}$ sites when $\mathrm{Ni}+\mathrm{Ru} \leq 50$ at. \% is not surprising, as it allows for the formation of strong $\mathrm{Ni}-\mathrm{Al}$ bonds.

In terms of the phase structure of the ternary alloy(s) bridging the two binary B2 phases NiAl and $\mathrm{RuAl}$, there are reports that suggest either a miscibility gap and phase separation for compositions near $\mathrm{Ni}_{25} \mathrm{Ru}_{25} \mathrm{Al}_{50}$ [9-11] or a single ternary $\mathrm{B} 2$ phase throughout [12-13]. While BFS Monte Carlo NN simulations, as described in Ref. 18 , clearly show the formation of the B2 
RuAl phase, as can be seen in Fig. 2.a, the results are just as clear for $\mathrm{Ni}_{25} \mathrm{Ru}_{25} \mathrm{Al}_{50}$, as shown in Fig. 2.b. The simulations show that both $\mathrm{Ru}$ and $\mathrm{Ni}$ share the same sublattice. The degree and type of ordering can be estimated from the coordination matrices $a$ and $b$, for nearest-neighbors (NN) and next-nearest-neighbors (NNN), respectively, where the matrix element $a_{i j}\left(b_{i j}\right)$ denotes the probability that an atom of species $i$ has an atom $j$ as a NN (NNN). If there is phase separation, it would be expected that atoms in the $\mathrm{Ru} / \mathrm{Ni}$ sublattice will have, mostly, atoms of their same species as NNN's. If there was a ternary ordered phase other than B2, the NNN coordination of $\mathrm{Ru}$ or $\mathrm{Ni}$ atoms would reflect this fact with an increasing number of NNN's of the other species. For example, the NNN coordination matrix for a Heusler $\mathrm{L} 2{ }_{1}$ ternary phase would maximize the value of $b_{N i R u}\left(=b_{R u N i}=1\right)$. Phase separation, on the other hand, would lead to a very small value of $b_{N i R u}$ (and $b_{R u N i}$ ), maximizing in turn, $b_{N i N i}$ (and $b_{R u R u}$ ). Instead, the results of the simulations reflect the existence of a $(\mathrm{Ru}, \mathrm{Ni}) \mathrm{Al} \mathrm{B} 2$ phase where $\mathrm{Ru}$ and $\mathrm{Ni}$ are randomly located throughout their own sublattice, in agreement with Liu et al. [12] and Horner et al. [13].

The BFS values of the lattice parameter for $\left(\mathrm{Ru}_{50-\mathrm{x}} \mathrm{Ni}_{\mathrm{x}}\right) \mathrm{Al}_{50}$ as a function of $\mathrm{Ni}$ concentration (in at.\%), $a(x)$, show a slight deviation with respect to the the average values obtained using Vegard's law [34], as shown in Fig. 3. Reported measurements of $a(x)[11,12]$ are also considered as having a linear behavior. The linear fit of the experimental values in Ref. 11 (normalized to the equilibrium B2 value $\left.a_{0}\right)$ is $a(x) / a_{0}=1-0.0006949 x$. In spite of the slight positive deviation from linearity, the best linear fit of the BFS prediction is almost identical, $a(x) / a_{0}=1-0.0007266 x$.

To further understanding of the behavior of the ternary alloys, it is possible to define within the framework of BFS, the role that each atom plays in $\left(\mathrm{Ru}_{50-\mathrm{x}} \mathrm{Ni}_{\mathbf{x}}\right) \mathrm{Al}_{50}$ as a function of $\mathrm{Ni}$ concentration, by separately computing the BFS energy contributions. Fig. 4 shows the strain, chemical and total energy contributions of $\mathrm{Ru}, \mathrm{Ni}$, and $\mathrm{Al}$ atoms to ternary RuNiAl alloys, computed as the average over all atoms of similar species. Ru atoms provide a favorable (i.e., $\varepsilon^{C_{<}}$ 0 , favoring alloying) chemical contribution to the total energy of formation, diminished by increasing strain as the $\mathrm{Ni}$ concentration increases. As a result, the role of $\mathrm{Ru}$ in favoring compound formation is diminished with increasing $\mathrm{Ni}$ content (Fig. 4.a). Ni atoms display the opposite behavior: as the concentration of $\mathrm{Ni}$ increases, the strain energy becomes substantially smaller as the average volume per atom in the alloy becomes closer to that of $\mathrm{Ni}$. The chemical contribution, which does not favor alloying, increases, but at a slower rate than the decrease in strain, resulting in a total contribution that does not favor the stability of the alloy (Fig. 4.b). Al 
atoms display a mild increase in strain with increasing $\mathrm{Ni}$ content, easily compensated by the growing (much more favorable than $\mathrm{Ru}$ ) chemical contribution, leading to a net decrease of the total energy (Fig. 4.c), which along with the chemical contribution from Ru ultimately favors the formation of ternary B2 compounds.

\section{Summary}

The BFS method for alloys has been used to model the structure of RuAl and the extension of the $\mathrm{B} 2$ phase fields from $\mathrm{NiAl}$ to $\mathrm{RuAl}$ in the $\mathrm{Ru}-\mathrm{Ni}-\mathrm{Al}$ system. The $\mathrm{BFS}$ analysis correctly predicts the melting temperature of $\mathrm{RuAl}$ and indicates a strong preference for $\mathrm{Ni}$ in $\mathrm{Ru}$ sites in $\left(\mathrm{Ru}_{50-\mathrm{x}} \mathrm{Ni}_{\mathrm{x}}\right) \mathrm{Al}_{50}$ alloys, and an almost equal probability for either site in Al-defficient alloys. The results indicate that the two phases are isostructural with a single $\mathrm{B} 2$ phase of varying $\mathrm{Ru}$ :Ni ratio bridging the binary compounds. The calculated lattice parameter for $\left(\mathrm{Ru}_{50-\mathrm{x}} \mathrm{Ni}_{\mathrm{x}}\right) \mathrm{Al}_{50}$ alloys, as a function of $\mathrm{Ni}$ contents, displays slight deviations from the average values, but in close agreement with experiment.

\section{Acknowledgments}

Fruitful discussions with N. Bozzolo are gratefully acknowledged. We thank P. Abel and J. Khalil for their help in preparing this manuscript. RDN wishes to acknowledge the additional support of N. Noebe. This work was financially supported by the HOTPC project at NASA Glenn Research Center, Cleveland, Ohio.

\section{References}

1. R. L. Fleischer, R. D. Field and C. L. Briant, Metall. Trans. A 22 (1991) 403.

2. R. L. Fleischer, Met. Trans. A 24 (1993) 227.

3. R. L. Fleischer and D. W. McKee, Met. Trans. A 24 (1993) 759.

4. R. Fleischer, Acta metal. mater. 41 (1993) 863. 
5. R. Fleischer, Acta metal mater. 41 (1993) 1197.

6. I. M. Wolff and G. Sauthoff, Acta mater. 45 (1997) 2949.

7. I. M. Wolff and G. Sauthoff, Met. Mat. Trans. A 27 (1996) 1395.

8. I. M. Wolff and G. Sauthoff, Met. Mat. Trans. A 27 (1996) 2642.

9. S. Chakravorty and D. R. F. West, Scripta Metall. 19 (1985) 1355.

10. S. Chakravorty and D. R. F. West, J. Mater. Sci. 21 (1986) 2721.

11. A. L. R. Sabariz and G. Taylor, Mat. Res. Soc. Symp. Proc. 460 (1997) 611.

12. K. W. Liu, F. M Muecklich, W. Pitschke, R. Birringer and K. Wetzig, Mat. Sci. Eng. A 313 (2001) 187.

13. I. J. Horner, N. Hall, L. A. Cornish, M. J. Witcomb, M. B. Cortie and T. D. Boniface, J. Alloys and Compounds 264 (1998) 173.

14. G. Bozzolo, R. D. Noebe, J. Ferrante, C. Amador, J. Comput.-Aided Mater. Design 6 (1999) 1;G. Bozzolo, R. D. Noebe, J. Ferrante, A. Garg, F. Honecy, C. Amador, J. Comput.-Aided Mater. Design 6 (1999) 33 , and references incorporated in both articles.

15. P. Blaha, K. Schwartz, J. Luitz J, WIEN97, Vienna University of Technology. Updated Unix version of the copyrighted WIEN code, P. Blaha, P. Schwartz, P. Sorantin, S. B. Trickey, Comput. Phys. Commun. 59 (1990) 399.

16. O. K. Andersen, Phys. Rev. B12 (1975) 3060.

17. G. Bozzolo, R. D. Noebe and C. Amador, Intermetallics 10 (2002) 149.

18. G. Bozzolo, J. Khalil and R. D. Noebe, Comp. Mat. Sci. (2002) (in press).

19. D. J. Singh, Phys. Rev. B 46 (1992) 14392.

20. P. Villars and L. D. Calvert, Pearson's Handbook of Crystallographic Data for Intermetallic Phases (American Society for Metals, Metals Park, OH, 1986).

21. W.-G. Jung, O. J. Kleppa, Met. Trans. B 23 (1992) 53.

22. R. Hultgren, P. D. Desai, D. T. Hawkins, M. Gleiser and K. K. Kelley, in Selected Values of the Thermodynamic Properties of Binary Alloys, American Society of metals, Metals Park, Ohio, 1973; O. Kubaschewski, E. L. Evans, C. B. Alcock, Metallurgical Thermochemistry, $4^{\text {th }}$. Edition (Pergamon Press, Oxford, 1967).

23. M. H. Yoo, T. Takasuga, S. Hanada, O. Izumi, Mater. Trans. JM, V 31 (1990) 435

24. R. Fleischer, D.M. Dimiduk, H.A. Lipsitt, Annu. Rev. Mater. Sci. 19 (1989) 231

25. K. Rzyman, Z. Moser, R. E. Watson, M. J. Weinert, J. Phase Equil. 19 (1998) 106. 
26. R. L. Fleischer, in Intermetallic Compounds, O. Izumi ed. (Japan Institute of Metals, Sendai, 1991, p. 157).

27. V. L. Moruzzi, A. R. Williams, J. F. Janak, Phys. Rev. B 10 (1974) 4856

28. A. R. Williams, J. Kuebler, C. D. Gelatt Jr., Phys. Rev. B 19 (1979) 6094.

29. D. N. Manh and D. G. Pettifor, Intermetallics 7 (1999) 1095.

30. I. Zou and C. L. Fu, Phys. Rev. B 51 (1995) 2115.

31. W. Lin, J.-H Xu and A. J. Freeman, J. Mater. Res. 7 (1992) 592.

32. A. Magnelli, L. E. Edshammar, T. Dagerhamn and S. Westman, Final Technical Report No. 1 on contract DA-91-591-EUC-3134 (AS 451442) (1964) p. 6.

33. D. N. Manh, A. T.Paxton, D. G. Pettifor and A. Pasturel, Intermetallics 3 (1995) 9.

34. L. Vegard, Z. Phys. 5 (1921) 17. 


\section{TABLE CAPTIONS}

Table 1: LAPW results for the lattice parameter, cohesive energy, and bulk modulus for the bcc phases of Ru, Al and Ni, the resulting equivalent crystal theory (ECT) parameters $\mathrm{p}, \alpha, l$ and $\lambda$ and the BFS perturbative parameters $\Delta_{\mathrm{AB}}$ and $\Delta_{\mathrm{BA}}$.

Table 2: Calculated (LAPW) properties compared to measured and other theoretical values for $\mathrm{NiAl}$ and RuAl.

Table 3: Nearest-neighbor (NN) and next-nearest-neighbor (NNN) coordination matrices for the Ru-Ni-Al simulation shown in Fig. 2.b. The matrix element in row $i$ and column $j$, denotes the probability that an atom of species $i$ has a NN (top matrix) or a NNN (bottom matrix) of species $j$, where $i$ (or $j$ ) $=1,2,3$ corresponds to $\mathrm{Ru}, \mathrm{Al}, \mathrm{Ni}$, respectively. 


\section{FIGURE CAPTIONS}

Fig. 1: Energy of formation (in $\mathrm{eV} /$ atom) vs. Ru concentration. The data points shown correspond to the lowest energy configuration found at each composition.

Fig. 2: Final state (room temperature) of Monte Carlo MC-NN simulations for (a) RuAl and (b) $\mathrm{Ni}_{25} \mathrm{Ru}_{25} \mathrm{Al}_{50} . \mathrm{Ru}, \mathrm{Ni}$, and $\mathrm{Al}$ atoms are denoted with white, dark, and light grey spheres, respectively.

Fig. 3: Comparison of experimental results and BFS predictions for the lattice parameter of $\left(\mathrm{Ru}_{50}\right.$ $\left.{ }_{x} \mathrm{Ni}_{\mathbf{x}}\right) \mathrm{Al}_{50}$ alloys as a function of $\mathrm{Ni}$ concentration. Experimental results are from Ref. 11. The dashed line indicates the results of Vegard's law.

Fig. 4: Individual average BFS contributions for a) $\mathrm{Ru}$, b) $\mathrm{Ni}$ and c) $\mathrm{Al}$ atoms in $\mathrm{a}\left(\mathrm{Ru}_{50-\mathrm{x}} \mathrm{Ni}_{\mathrm{x}}\right) \mathrm{Al}_{50}$ alloy, as a function of $\mathrm{Ni}$ concentration. In each case, the strain (Triangle up), chemical (triangle down) and total (solid disk) energies are shown. 


\begin{tabular}{|c|c|c|c|c|c|c|c|}
\hline & \multirow{2}{*}{$\begin{array}{c}\text { Lattice } \\
\text { parameter } \\
(\AA) \\
\end{array}$} & \multirow{2}{*}{$\begin{array}{c}\text { Cohesive } \\
\text { energy } \\
(\mathrm{eV})\end{array}$} & \multirow{2}{*}{$\begin{array}{c}\begin{array}{c}\text { Bulk } \\
\text { modulus }\end{array} \\
(\mathrm{GPa}) \\
\end{array}$} & \multicolumn{4}{|c|}{ ECT parameters } \\
\hline & & & & $\mathbf{p}$ & $\alpha\left(\AA^{-1}\right)$ & $l(\AA)$ & $\lambda(\AA)$ \\
\hline $\mathrm{Ru}$ & 3.0484 & 6.5514 & 294.52 & 8 & 3.5974 & 0.2508 & 0.7048 \\
\hline $\mathrm{Al}$ & 3.2400 & 3.4225 & 69.37 & 4 & 1.7609 & 0.3623 & 1.0180 \\
\hline $\mathrm{Ni}$ & 2.7985 & 5.6001 & 198.35 & 6 & 3.0597 & 0.2949 & 0.8288 \\
\hline \multicolumn{8}{|c|}{ BFS parameters (in $\AA^{-1}$ ) } \\
\hline$\Delta_{\mathrm{RuAl}}$ & -0.04186 & & $\Delta_{\mathrm{RuNi}}$ & 0.28503 & & $\Delta_{\mathrm{NiAl}}$ & -0.04288 \\
\hline$\Delta_{\text {AlRu }}$ & -0.02483 & & $\Delta_{\mathrm{NiRu}}$ & -0.04361 & & $\Delta_{\mathrm{AlNi}}$ & 0.10287 \\
\hline
\end{tabular}

Table 1 


\begin{tabular}{lllll}
\hline & & \multicolumn{1}{c}{$a_{0}(\AA)$} & \multicolumn{1}{c}{$B(\mathrm{GPa})$} & \multicolumn{1}{c}{$\Delta H$ (ev/atom) } \\
\hline NiAl & Expt. & $2.8864[20]$ & $158-166[23], 189[24]$ & $0.61[22], 0.6831[25]$ \\
& LAPW & 2.89 & 185 & 0.79 \\
& (This work) & & & \\
& Other calcs. & $2.86[26], 2.88[27,28]$, & $200[26], 170[27]$, & $0.697[29], 0.68[30]$, \\
& & $2.839[29]$ & $184[29]$ & $0.61[19], 0.733[31]$ \\
& & & \\
RuAl & Expt. & $3.03[20], 2.99[26]$, & $208[26]$ & $1.28[21]$ \\
& $2.95[32]$ & 203 & 0.99 \\
& & & & \\
& LAPW & 3.005 & $223[29], 220[31]$ & $0.61[29], 0.776[31]$, \\
& & & $0.81[33]$ \\
\hline
\end{tabular}

Table 2 


\begin{tabular}{cc|ccc}
$\mathrm{NN}$ & $i / j$ & $\mathrm{Ru}$ & $\mathrm{Al}$ & $\mathrm{Ni}$ \\
\hline & $\mathrm{Ru}$ & 0.000 & 0.992 & 0.008 \\
$\mathrm{Al}$ & 0.496 & 0.016 & 0.488 \\
& $\mathrm{Ni}$ & 0.008 & 0.976 & 0.016 \\
& & & & \\
$\mathrm{NNN}$ & & & $\mathrm{Al}$ & $\mathrm{Ni}$ \\
\hline & $\mathrm{Ru}$ & $\mathrm{Ru}$ & $\mathrm{Al}$ & 0.512 \\
& $\mathrm{Al}$ & 0.004 & 0.985 & 0.011 \\
& $\mathrm{Ni}$ & 0.512 & 0.023 & 0.4653
\end{tabular}

Table 3 


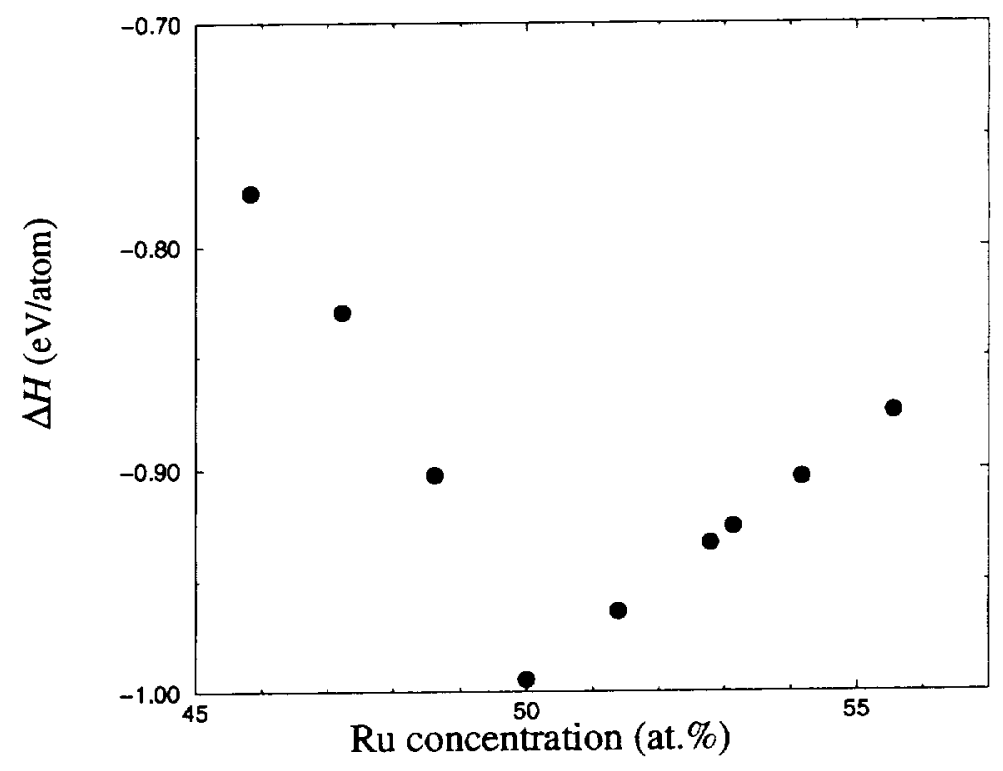

Fig. 1 


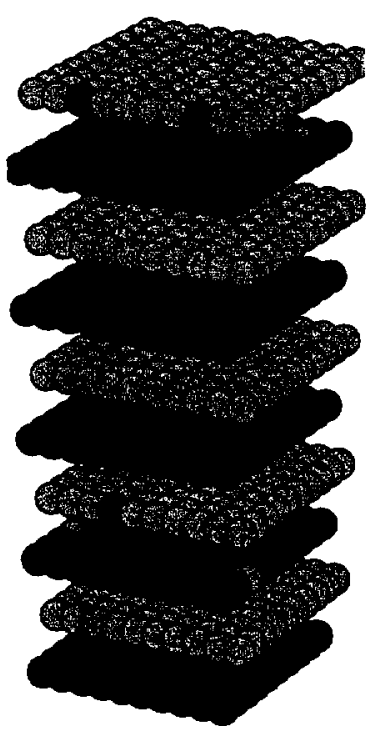

(a)

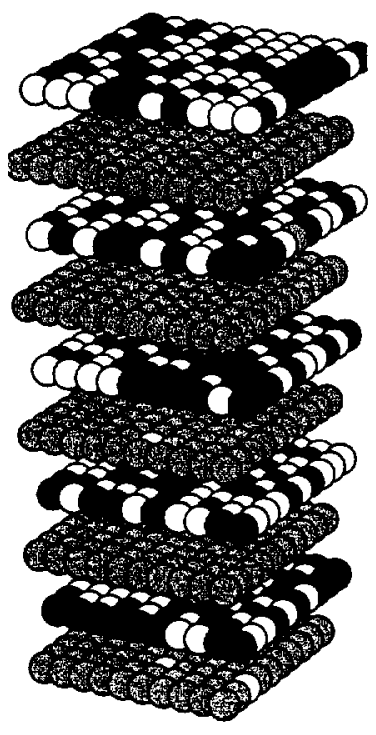

(b)

Fig. 2 


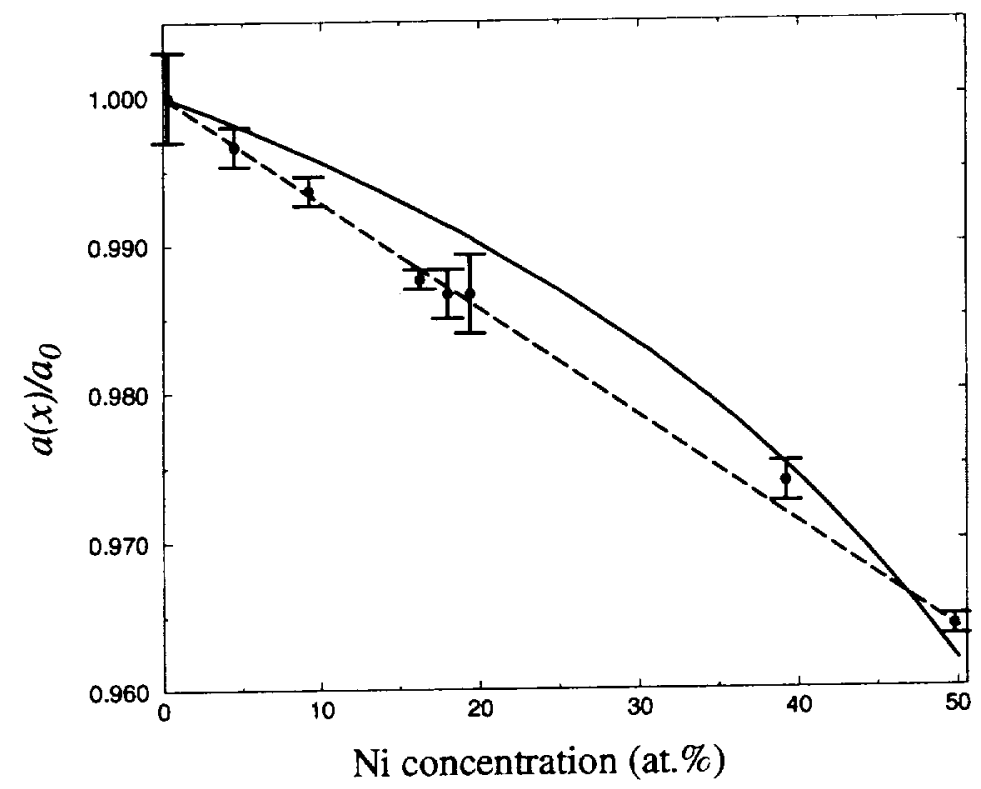

Fig. 3 
(a)

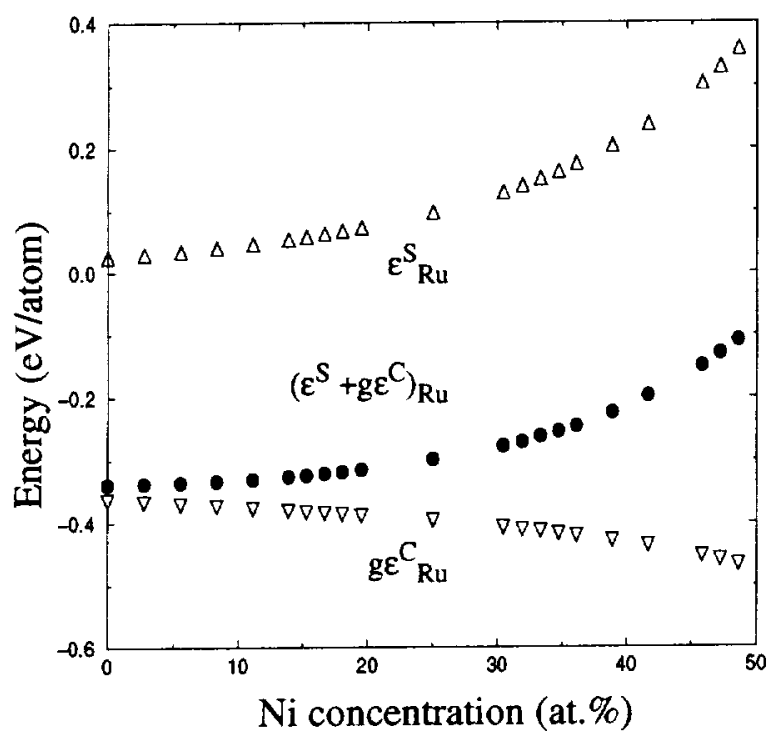

(b)

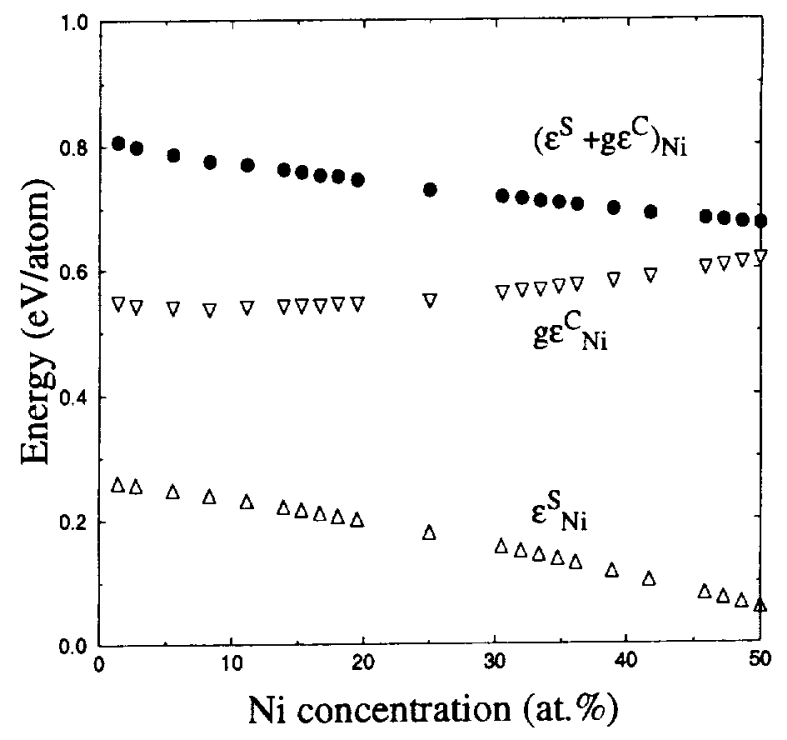

(c)

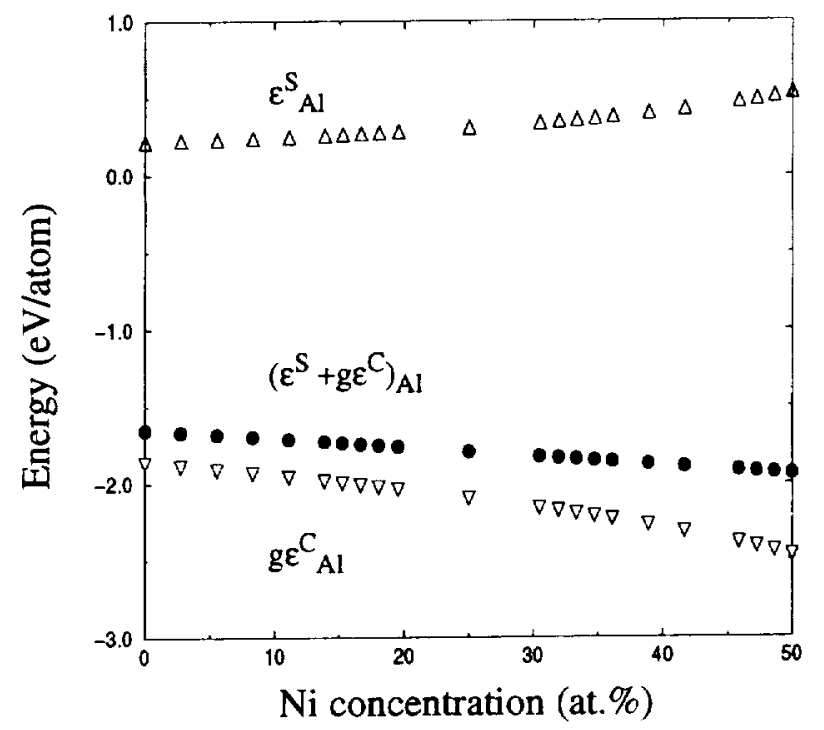

Fig. 4 